San Jose State University

SJSU ScholarWorks

Master's Theses

Master's Theses and Graduate Research

Summer 2020

\title{
The Moderating Effect of Leadership Adaptability on the Relationship between Employee Adaptability and Job Performance
}

Justine Davis

San Jose State University

Follow this and additional works at: https://scholarworks.sjsu.edu/etd_theses

\section{Recommended Citation}

Davis, Justine, "The Moderating Effect of Leadership Adaptability on the Relationship between Employee Adaptability and Job Performance" (2020). Master's Theses. 5122.

DOI: https://doi.org/10.31979/etd.j7qp-j5jj

https://scholarworks.sjsu.edu/etd_theses/5122

This Thesis is brought to you for free and open access by the Master's Theses and Graduate Research at SJSU ScholarWorks. It has been accepted for inclusion in Master's Theses by an authorized administrator of SJSU ScholarWorks. For more information, please contact scholarworks@sjsu.edu. 


\title{
THE MODERATING EFFECT OF LEADERSHIP ADAPTABILITY ON THE RELATIONSHIP BETWEEN EMPLOYEE ADAPTABILITY AND JOB PERFORMANCE
}

\author{
A Thesis \\ Presented to \\ The Faculty of the Department of Psychology \\ San José State University \\ In Partial Fulfillment \\ of the Requirements for the Degree \\ Master of Science
}

by

Justine L. Davis

August 2020 
(C) 2020

Justine L. Davis

ALL RIGHTS RESERVED 
The Designated Thesis Committee Approves the Thesis Titled

THE MODERATING EFFECT OF LEADERSHIP ADAPTABILITY ON THE RELATIONSHIP BETWEEN EMPLOYEE ADAPTABILITY AND JOB PERFORMANCE

by

Justine L. Davis

APPROVED FOR THE DEPARTMENT OF PSYCHOLOGY

SAN JOSÉ STATE UNIVERSITY

August 2020

Dr. Howard Tokunaga

Department of Psychology

Dr. Megumi Hosoda

Department of Psychology

Michelle Savanyo, M.S.

Human Resources, Equinix LLC 


\title{
ABSTRACT \\ THE MODERATING EFFECT OF LEADERSHIP ADAPTABILITY ON THE RELATIONSHIP BETWEEN EMPLOYEE ADAPTABILITY AND JOB PERFORMANCE
}

\author{
by Justine L. Davis
}

The purpose of this study was to investigate the potential moderating effect of leadership adaptability on the relationship between employee adaptability and employee job performance. Previous research explored leadership adaptability as a mediator; however, there was a significant gap exploring leadership adaptability as a moderator. Participants were recruited via online social and personal networks. 125 participants completed a self-report survey consisting of items measuring employee adaptability, perceived manager adaptability and job performance. Results did not show perceived manager adaptability as a moderator of the relationship between employee adaptability and job performance. The results indicated that there were significant relationships between employee adaptability, perceived manager adaptability, and job performance. Highly adaptable employees reported better job performance than less adaptable employees. The results also indicated that highly adaptable employees report better job performance when they rate their managers as less adaptable. These findings suggest that evaluating employee adaptability and perceived manager adaptability may have important implications for organizations who are seeking to maximize the potential of highly adaptable employees. 


\section{ACKNOWLEDGMENTS}

First, I would like to thank my thesis committee for their constant support in helping me complete this thesis. Howard Tokunaga, thank you for your guidance and encouragement throughout the thesis process and my time as a graduate student at SJSU. Megumi Hosoda, thank you for your valuable input in reading my paper and for all of the support you have offered me while going through the graduate program. Michelle Savanyo, thank you for your mentorship and keen advice during my internship and thesis process. I would also like to thank my friends and family for supporting me tirelessly throughout my graduate school experience. Lastly, I would like to thank my fiancé Colton for cheering me on and offering unrelenting encouragement every step of the way. Thank you for everything. 


\section{TABLE OF CONTENTS}

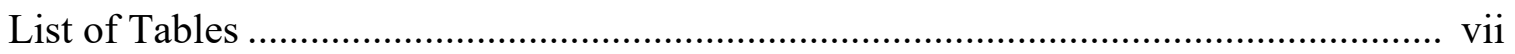

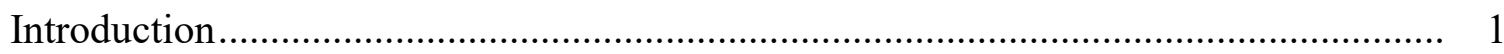

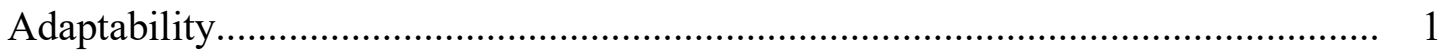

Employee Adaptability …………………………………………………….... 2

Career building-oriented adaptability ................................................................. 2

Job task performance-oriented adaptability ........................................................ 3

Employee Adaptability as a Predictor Variable ......................................................... 9

Moderation and Mediation of the Relationship Between Employee

Adaptability and Job Performance.......................................................................... 12

Leadership Adaptability ................................................................................. 16

Leadership Adaptability as a Moderator Variable .................................................. 17

Purpose of the Current Study ............................................................................ 19

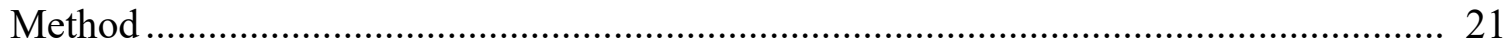

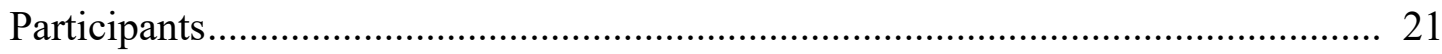

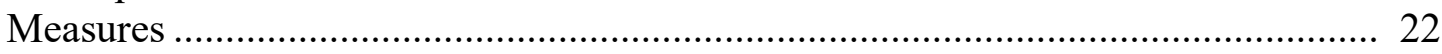

Job task performance-oriented adaptability of the employee .............................. 22

Job task performance-oriented adaptability of the manager ................................. 24

Employee job performance ……………………......................................... 25

Participant demographics................................................................................. 27

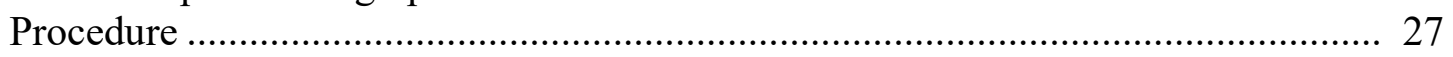

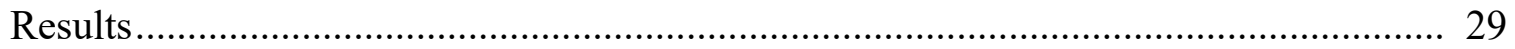

Descriptive Statistics.................................................................................. 29

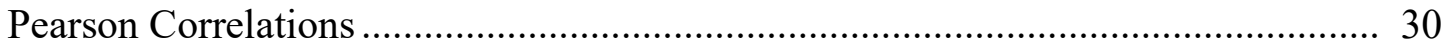

Test of Hypothesis ............................................................................................... 30

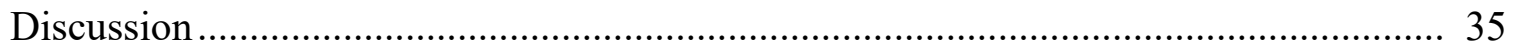

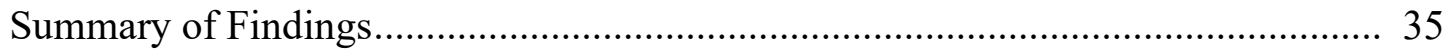

Theoretical Implications ................................................................................... 36

Practical Implications................................................................................... 39

Strengths ............................................................................................... 42

Limitations and Suggestions for Future Research ................................................. 43

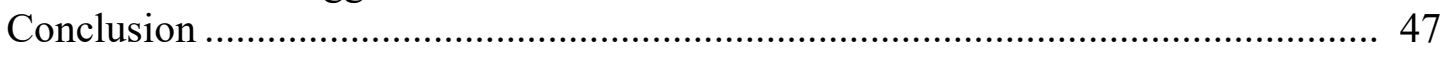

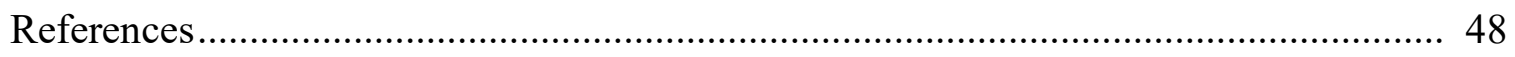

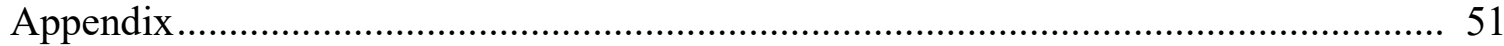

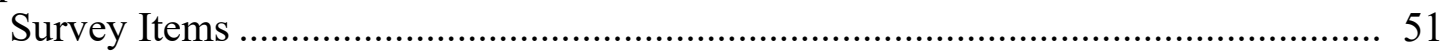




\section{LIST OF TABLES}

Table 1. Demographic Characteristics of the Participants.......................................... 22

Table 2. Means, Standard Deviations, and Bivariate Correlations Among Variables..... 29

Table 3. Hierarchical MRC for the Moderating Effect of Perceived Manager

Adaptability (Overall Job Performance) .................................................... 32

Table 4. Hierarchical MRC for the Moderating Effect of Perceived Manager Adaptability (Global Self-Evaluation of Job Performance)............................. 34 


\section{Introduction}

Adaptability is a trait researchers have studied to better understand how people respond to new, changing, or uncertain circumstances, situations, and conditions (Martin, Nejad, Colmar, \& Liem, 2012). One environment where individuals often encounter new circumstances and situations is the workplace. Studies have shown that adaptability in employees has positive relationships with improved work-related outcomes such as turnover intentions, leader potential, and job performance (e.g., Dries \& Pepermans, 2012; Kim, Kim, Kim, \& Kim, 2017; Parent \& Levitt, 2009; Sony \& Mekoth, 2016).

The existing body of literature has focused primarily on the direct relationship between employee adaptability and job performance, whereas few studies have examined the mediation or moderation of this relationship (Cullen, Edwards, Casper, \& Gue, 2013; Wang, Zhan, McCune, \& Truxillo, 2011). A significant gap in the literature exists around moderation of the relationship between employee adaptability and job performance. This study aimed to address that gap by examining the moderating effect of leadership adaptability on the relationship between employee adaptability and job performance.

\section{Adaptability}

People are faced with new and changing circumstances every day and in all parts of their lives. They may deal with unpredictable traffic conditions, health issues, weather patterns, or social interactions. In order to successfully navigate and deal with these unfamiliar circumstances, people must be adaptable.

The work of Martin, Nejad, Colmar, and Liem (2012) defines adaptability as an individual's capacity to constructively regulate psycho-behavioral functions in response 
to new, changing and/or uncertain circumstances, conditions, or situations (Martin et al., 2012). Adaptability may be manifested as an individual's reaction to changing circumstances, the speed at which an individual adjusts behavior to fit a new situation, or as an individual's emotional response to unexpected circumstances.

People exhibit varying degrees of adaptability. A highly adaptable individual is not upset by unexpected changes and may be considered "even-keeled" or "steady." For example, if a planned event is canceled at the last minute, an individual who is highly adaptable will find other activities, will not feel distressed about the sudden change, and will eagerly participate in alternate activities. Conversely, a less adaptable individual may be unsettled by the unexpected change, may be perceived as "rigid" or "obstinate," might struggle to come up with other activities, or may not be open to alternative activities.

\section{Employee Adaptability}

One place where people often encounter uncertain circumstances is in the workplace. In order to perform their jobs, employees must be adaptable in their task proficiency, communication skills, personal discipline, effort, teamwork, leadership, and management. Employee adaptability is thus more specific than general adaptability. It has been researched in regard to two types: career building-oriented employee adaptability, and job task performance-oriented employee adaptability.

Career building-oriented adaptability. Savickas (1997) examined career building-oriented adaptability using career construction theory. This theory defines career building-oriented employee adaptability as the readiness to cope with predictable tasks of 
preparing for and participating in the work role as well as unpredictable adjustments prompted by changes in work or working conditions.

Career building-oriented adaptability is a higher-order construct with four subdimensions: concern, control, curiosity, and confidence (Savickas, 1997). Concern is the extent to which people prepare and plan for their future careers. For example, employees demonstrate concern when they cross-train and learn skills that may not be directly related to their current role. Control refers to the extent to which individuals take responsibility for vocational activities through effort, self-discipline, and persistence. Employees high in control will seek out training rather than wait for management to direct the training. Curiosity refers to the extent to which an individual explores other occupational roles and situations to prepare for career path opportunities. One example of employees demonstrating curiosity is talking with colleagues in other roles to learn more about how their work differs from the employees' work. Confidence is the extent to which individuals believe in their ability to pursue career goals and make career decisions. Employees high in confidence see training as a positive opportunity to grow, whereas employees low in confidence perceive training as a need to survive a negative change in their work (Jiang, 2016).

Job task performance-oriented adaptability. Pulakos, Arad, Donovan, and Plamondon (2000) researched the adaptability requirements of different jobs to develop a multidimensional construct of behavior that is generalizable across many kinds of occupations. They defined job performance as being synonymous with behavior in adherence to the job performance model defined by Campbell, McCloy, Oppler, and 
Sager (1993). Pulakos et al. (2000) defined adaptive performance as adapting one's behavior to meet the requirements of a new environment, circumstance, or event at work. Their goal was to develop a taxonomy of job task performance-oriented adaptability by analyzing the adaptability requirements of various jobs. They conducted two studies to meet this goal. The first study analyzed over 1,000 critical incidents from 21 different jobs to create an eight-dimension taxonomy of adaptability requirements employees encounter on the job: (1) solving problems creatively, (2) dealing with uncertain and unpredictable work situations, (3) learning work tasks, technologies, and procedures, (4) demonstrating interpersonal adaptability, (5) demonstrating cultural adaptability, (6) handling work stress, (7) handling work emergencies or crises, and (8) demonstrating physically-oriented adaptability.

The first dimension, solving problems creatively, is defined as developing creative solutions to novel or difficult problems. One example behavior of employees high in this dimension is devising innovative solutions when the resources needed to complete a project are not sufficient.

The second dimension, dealing with uncertain and unpredictable work situations, is defined as adjusting to and dealing with circumstances one has not encountered before and where the normal behavioral contexts may not apply to guide one's actions. For example, employees high in this dimension will effectively adjust project plans when the project sponsor decides to take the project in a new direction.

The third dimension, learning work tasks, technologies, and procedures, refers to anticipating future needs and adapting to changing job requirements by learning. An 
example behavior of employees high in this dimension is eagerly learning how to use a new project management application midway through a project.

The fourth dimension, demonstrating interpersonal adaptability, is defined as adjusting one's interpersonal style to achieve a goal or work effectively with new people. For example, employees high in this dimension easily work with others who are more or less extraverted than themselves and are open to others' viewpoints and opinions.

The fifth dimension, demonstrating cultural adaptability, is defined as performing effectively in new cultures and successfully integrating into a new culture or environment by understanding and willingly behaving in accordance with accepted customs, values, rules, and structures. An example behavior of employees high in this dimension is working well in multicultural teams and not offending teammates by violating their cultural norms.

The sixth dimension, handling work stress, is defined as remaining cool and composed when faced with difficult circumstances or a highly demanding workload or schedule. An example behavior of employees high in this dimension is remaining calm and professional when a project deadline is suddenly advanced.

The seventh dimension, handling work emergencies or crises, is defined as reacting to life threatening, dangerous, or emergency situations with proper urgency, emotional control, and maintaining a clear head to make good split-second decisions. Employees high in this dimension step up and take appropriate action when a coworker experiences a medical emergency such as a seizure or heart attack. 
The eighth dimension, demonstrating physically-oriented adaptability, is defined as adjusting to challenging environmental states such as extreme heat, humidity, cold, or dirtiness as well as adjusting one's physical strength to complete tasks necessary for the job. For example, employees high in this dimension perform well even after moving to a new climate.

The second study conducted by Pulakos et al. (2000) validated the above eight dimensions via a survey administered to over 1,000 participants in the military, government, law enforcement, and private sector. The items in the survey asked participants to describe various ways they approached situations where they were required to adapt their behavior at work, as determined by the taxonomy of eight adaptive performance dimensions developed in the first study. Participants were asked to indicate the importance and the amount of time spent on each item. An example of these items is "Tailoring one's behavior depending on others' needs and interests to help them feel more comfortable." Participants rated the importance of this behavior on a five-point scale ranging from 1 ("This is of minor importance compared to other things I do on my job") to 5 ("This is extremely important compared to other things I do on my job"). Participants then rated the amount of time spent performing the behavior on a five-point scale ranging from 1 ("I spend much less time on this than on other things I do for my job") to 5 ("I spend much more time on this than I do on other things I do on my job").

Results of confirmatory factor analysis showed that the items in the survey were a good fit to the eight proposed dimensions. Pulakos et al. (2000) concluded that these eight dimensions were representative of adaptive performance situations across many 
different occupations. They suggested that future research focus on how employees adapt to various adaptive performance situations they find themselves in because of their jobs.

The work of Pulakos et al. (2000) showed how different jobs required employees to perform adaptably in different ways through their eight dimensions. However, their work focused on the job itself, not the employee. This was because their intention was to investigate the various conditions of jobs that required employees to adapt to be successful, rather than how the employees actually adapted to those conditions. Ployhart and Bliese (2006) recognized there was a gap between the adaptability required by a job and the actual adaptability demonstrated by the employee. They hypothesized that the adaptive performance capacity of employees could be measured in each of the eight dimensions, implying that adaptability is a trait of an employee influenced by internal factors, such as disposition, willingness, ability, and skill, and external factors, such as the environment, the task itself, and the previous experiences the employee has had.

Ployhart and Bliese (2006) examined both the adaptive performance requirements of jobs and how employees rose to meet those requirements by adapting their behavior. They defined job task performance-oriented employee adaptability as representing an individual's ability, skill, disposition, willingness, and/or motivation to change or fit different tasks, social, and environmental features. They developed a theory called IADAPT to support this definition.

The I-ADAPT theory is based on the dimensions proposed by Pulakos et al. (2000), but focuses on the adaptability of the employees themselves rather than on the situation requiring adaptability presented in the workplace. I-ADAPT claims certain individuals 
are more adaptable and thus respond to the various dimensions of job task performanceoriented adaptability differently than less adaptable individuals. For example, an employee who is more adaptable will be less inclined to see an unpredictable event at work as stressful and will respond to the unpredictability with innovative solutions and problem solving strategies. A less adaptable employee will see the same situation as stressful and will be less creative when confronting the uncertain circumstances.

Ployhart and Bliese (2006) developed a measure called the I-ADAPT-M to assess job task performance-oriented employee adaptability. This measure filled the gap left by Pulakos et al. (2000) by developing a tool researchers could use to evaluate individuals. Their goal was to create a measurement system that was both comprehensive and of reasonable length. The researchers recognized that for the survey to be used in real world applications, it had to be quick and easy to fill out, while still capturing the depth of information needed for accurate analyses. They chose a self-report inventory style as it was easy to administer and score. The items in the measure were designed to assess the eight dimensions defined by Pulakos' et al. (2000) but were written to focus on the performance of the individual within each dimension. The items were crafted to be generalizable to any occupation.

The current study used Ployhart and Bliese (2006)'s measure of job task performance-oriented employee adaptability as it encompasses relevant employee behaviors. However, two of the eight dimensions, handling work emergencies and physically oriented adaptability, are not relevant to this study and thus are not included. While these two dimensions are appropriate for occupations such as firefighters or 
soldiers where life-threatening situations or challenging environmental states are common occurrences, in the corporate settings this study was conducted these dimensions are irrelevant.

\section{Employee Adaptability as a Predictor Variable}

Employee adaptability has been related to various employee-related outcomes. Dries and Pepermans (2012) conducted two studies to develop a model of leadership potential consisting of four quadrants: analytical skills, learning agility, drive, and emergent leadership. Job task performance-oriented adaptability was noted as an important factor in the learning agility quadrant, which was defined as consisting of three factors; willingness to learn (actively looking for novel experiences to enhance learning), emotional intelligence (maintaining a stable self-concept in stressful or new situations), and adaptability (being open to change when novel circumstances require it). The results of the study showed that overall job task performance-oriented adaptability was highly correlated with the learning agility quadrant, indicating that job task performanceoriented adaptability was an important component of leadership potential.

Kim, Kim, Kim, and Kim (2017) looked at job task performance-oriented adaptability in casino workers in South Korea and its relationship to organizational drivers such as schedule flexibility and career development opportunities, as well as organizational outcomes such as job performance and turnover intention. Over 480 casino workers took a self-administered survey assessing their adaptability and the company's career development opportunities. The results of the study showed that more adaptable employees had fewer turnover intentions than less adaptable employees. The authors 
concluded that more adaptable employees were good for the overall health of the organization because they performed well under pressure and in uncertain circumstances (such as when faced with an irate gambler), and were more likely to stay with the company, which was beneficial to the casino in the long run. The authors also noted that employers might feel their more adaptable employees are more reliable and thus do not need to be as closely managed as their less adaptable employees. This was seen as beneficial to the casino company as managers could spend more time and money improving the gambling experience for their customers than constantly searching for, hiring, and training new employees.

Employee adaptability has also been related to job performance, which is the focus of this study. Kim et al. (2017) found job task performance-oriented adaptability was positively related to self-reported job performance, meaning more adaptable casino employees performed better at their jobs. The authors noted that this correlation was particularly strong for casino dealers, meaning that less adaptable employees were less likely to perform well as a dealer than in other more predictable casino positions.

Sony and Mekoth (2016) studied the relationship between job task performanceoriented adaptability and job performance in front-line employees in the service industry. In a sample of 500 front-line employees working in power utility positions in India, a positive correlation was found between job task performance-oriented adaptability and job performance. The authors noted that adaptable front-line employees are a critical asset to organizations as they improve the experience for the customer. Customers are more satisfied when front line employees adapt to unpredictable situations because the 
customers feel confident that employees can handle unusual circumstances. Adaptable front-line employees also save the company money as they reduce the amount of time needed to resolve issues.

Parent and Levitt (2009) studied managers' and employees' perceptions of the benefits of job task performance-oriented adaptability in relation to job performance. They collected data from a large manufacturing company in the United States that was undergoing major changes. The change state of the organization was important to the researchers as it amplified circumstances where job task performance-oriented adaptability would be required for employees. The participants were surveyed about their perceptions of the importance of job task performance-oriented adaptability during the ongoing changes at the company. The results of the survey indicated that both managers and employees felt job task performance-oriented adaptability was important for job performance. Employees who reported being more adaptable reported performing better than their less adaptable coworkers. Managers corroborated those findings by reporting that their more adaptable employees performed better than their less adaptable employees.

In summary, the body of literature on employee adaptability as a predictor variable is considerable and employee adaptability has been related to workplace-related outcomes that are beneficial to both organizations and employees. In particular, there is much empirical support for the relationship between job task performance-oriented adaptability and job performance. However, the research cited above focused only on the direct 
relationship between job task performance-oriented adaptability and job performance and neglected to investigate factors that might influence this relationship.

\section{Moderation and Mediation of the Relationship Between Employee Adaptability and Job Performance}

Moderation and mediation are important to consider when researching the relationships between predictor and outcome variables. Many relationships may be influenced by the presence of a mediator or moderator. Mediators help explain why the relationship exists and moderators affect the relationship's strength or direction.

When looking at the employee adaptability-to-job performance relationship, it is understood that the relationship may be a function of additional variables. Cullen, Edwards, Casper, and Gue (2013) suggested that perceived organizational support mediates the relationship between employee adaptability and job performance. Perceived organizational support is defined as employees' perceptions of the extent to which their organization provides adequate resources, values them as individuals, and is likely to reward their performance and help them during difficult times such as during organizational change (Eisenberger, Huntington, Hutchinson, \& Sowa, 1986; Rhoades \& Eisenberger, 2002; Shore \& Shore, 1995).

Cullen et al. (2013) hypothesized that perceived organizational support would mediate the relationship between individual adaptability and job performance. The authors predicted that employees who are high in adaptability will form more favorable perceptions of organizational support than employees low in adaptability. Adaptable individuals proactively take responsibility for adjusting to changes in the organization. Employees who feel their organization supports them and values them are be more likely 
to view the organization in a positive way, and thus will be more likely to reach out to the organization and receive the support they need to make adjustments in their work task performance. The organization will appreciate their willingness to adapt and learn and will reward them with praise and encouragement, which will result in better job performance. In contrast, employees low in adaptability tend to view new situations and circumstances more negatively than employees high in adaptability. They are more likely to view organizational changes as a threat and will feel negatively toward the organization for challenging them unjustly. They would be more likely to withhold effort, which would result in lower job performance.

The authors surveyed employees and managers at a pharmaceutical company about the adoption of a new technology. They focused on employees' and managers' adaptability during recent organizational changes and the extent to which they felt the organization supported them through the changes. The authors then obtained performance ratings from organizational records. Their results of their work found support for mediation of the employee adaptability to job performance relationship by perceived organizational support.

These findings have important implications for organizations. In the Cullen et al. (2013) study, perceived organizational support mediated the relationship and was believed to combat negative organizational outcomes that may arise when changes are introduced. This finding can be applied during times of organizational change to better cope with potential job performance issues by focusing on the support an organization gives to its employees; this support may lessen potential negative effects on performance. 
Wang, Zhan, McCune, and Truxillo (2011) looked at longitudinal data of Chinese employees who were newcomers in their organization to examine the mediation effects of person-environment fit on the relationship between employee adaptability and workrelated outcomes. Measuring their job task performance-oriented adaptability, the authors examined how the employees' person-environment fit, which is defined as the perceived compatibility between an individual and their environment (Kristof-Brown, Zimmerman, \& Johnson, 2005) mediated the relationship between the employees' adaptability and work related outcomes such as job performance, job satisfaction, and turnover intentions.

Wang et al. (2011) argued that person-environment fit might play an important role in bridging the gap between the beneficial effects of newcomers' adaptability and their work-related outcomes. The authors hypothesized that more adaptable individuals would be more likely to take actions to fit into their new environment, such as actively learning new skills in order to meet new work task demands, than less adaptable individuals. Furthermore, highly adaptable individuals would be more likely than less adaptable individuals to feel they could fit their new environments, leading to increased perceptions of positive person-environment fit. These positive perceptions would then lead to more positive work related outcomes for highly adaptable newcomers than for less adaptable newcomers who would be less likely to perceive their fit with their new environments as positive.

Wang et al. (2011) surveyed 813 new employees at a large corporation in China over a three-month time span. At Time 1, employees self-reported their job task performanceoriented adaptability and their perceptions of their person-environment fit. At Time 2, 
employees self-reported their perceptions of their person-environment fit, their job satisfaction, and their turnover intentions. Their supervisors were also surveyed at this time and provided ratings of job task performance for their subordinates.

The authors reported that after controlling for demographic and personality variables, person-environment fit mediated the relationship between the job task performanceoriented adaptability and the work-related outcomes of new employees. Highly adaptable newcomers perceived a better fit with their new environments and thus were more satisfied, performed better, and had fewer turnover intentions than newcomers with low job task performance-oriented adaptability and negative perceptions of their fit with their new environment. The authors noted the results of the study had practical implications, suggesting that organizations measure newcomers' job task performance-oriented adaptability when hired to better understand and support them as they onboard into their new jobs.

To summarize, mediation has been studied, but there is a lack of research on the moderation of the employee adaptability to job performance relationship. This gap in the literature is important to note as there could be many factors that may amplify or weaken the relationship. Understanding what moderators may affect the relationship has both academic and practical implications. Academic researchers may find that a moderator explains the relationship between employee adaptability and job performance in particular settings. Managers may be able to adapt performance improvement plans, workforce planning, or talent reviews to account for a moderating effect of another variable. One such variable could be leadership adaptability. 


\section{Leadership Adaptability}

Leadership adaptability is defined as individual's ability, skill, disposition, willingness, and/or motivation to change or fit different tasks, social, and environmental features (Ployhart \& Bliese, 2006) and that the individual is in a leadership position. Leadership adaptability is a critical characteristic that enhances leaders' effectiveness and has several significant relationships to performance outcomes. Using the definition of adaptive performance provided by Pulakos et al. (2000), Bartone, Kelly, and Matthews (2013) collected data from West Point military cadets and related their job task performance-oriented adaptability with military leadership performance grades based on an index of traditional military performance. They found that cadets who were more adaptable were more effective leaders than less adaptable cadets. According to their research, leadership adaptability had a direct relationship with leadership effectiveness

Hyllengren (2017) argued that adaptable leaders have more positive outcomes during unexpected events than less adaptable leaders. Hyllengren conducted interviews with Swedish soldiers and military officers in order to develop and administer a questionnaire to 193 Swedish soldiers who described how adaptable their officers' behavior was during an unexpected event and how their behavior affected the outcome of the event. These results imply that officers whose behavior was rated as more adaptable during unexpected threatening events were more likely to have a favorable outcome than officers whose behavior was less adaptable. This implies more adaptable leaders are more effective at leading their team to positive end results after encountering new and uncertain circumstances, meaning better performance overall. Less adaptable leaders are less likely 
to lead their team to positive end results after an unexpected event. This is an important difference in military jobs, where poor performance during unexpected threatening events could have fatal consequences.

These two studies illustrate that adaptive performance is critical to leadership effectiveness and team performance. There is empirical evidence that supports a positive relationship between a leader's adaptable behavior and the overall performance of their team. Organizations find this relationship beneficial to their overall operation because adaptable leaders can pivot quickly when faced with unexpected situations and circumstances that would otherwise slow down or stop organizational functioning. With this in mind, it is in the best interest of both academic researchers and organizations to understand the effect of leadership adaptability to maximize the effectiveness of their leaders.

\section{Leadership Adaptability as a Moderator Variable}

The work of Bartone et al. (2013) and Hyllengren (2017) has established direct relationships between leadership adaptability and leader effectiveness and team performance. However, there is a gap in the literature around the moderating effect of leadership adaptability on other relationships. Understanding leadership adaptability as a moderator is important as it could influence the relationship between employees' job task performance-oriented adaptability and job performance.

Why might leadership adaptability be a moderator of the relationship between employees' job task performance-oriented adaptability and job performance? The research around demography championed by Tsui and her collaborators lends support 
(Tsui, Porter \& Egan, 2002). The authors cited social categorization theory (Turner, $1985 ; 1987)$ which states that people use social categories to place themselves and those like them into a favorable in-group and those dissimilar from themselves into an unfavorable out-group. They posited that initial categorization by supervisors and subordinates might lead to biases that influence the quality of the relationship between them. More specifically, when there are demographic similarities between supervisors and subordinates, supervisors may give these subordinates preferential treatment, such as increased positive reinforcement, more frequent feedback, and additional training opportunities. At the same time, subordinates may be categorizing their supervisors and developing implicit favorable biases towards demographically similar supervisors. Subordinates may find supervisors who are similar to them more attractive than dissimilar supervisors and may respond by working harder and contributing more to the organization.

Tsui et al. (2002) evaluated 335 supervisor-subordinate dyads from ten diverse companies in the United States. They surveyed both parties on their similarities and asked supervisors to rate their subordinate's extra-role behaviors. The results of the study showed that demographic similarities between supervisors and subordinates positively affected the subordinates' extra-role behaviors; subordinates were more likely to help their co-workers and voluntarily take on learning opportunities to increase their value to the organization when they were similar in age, educational level, tenure, and gender to their supervisor. 
The results of Tsui et al. (2002) provide empirical support for the effects of similarities between leaders and their subordinates. If demographic similarities are enough to impact subordinates' behaviors, similarities in employees' and leaders' adaptability may also impact employees' job performance. Subordinates may view their supervisor's adaptable behaviors as increasing the supervisor's effectiveness as a leader. The subordinate may then wish to emulate their leader's adaptability in order to be as effective as their leader in their work tasks. Leaders may recognize the importance of adaptability and may demonstrate it more frequently to model a critical skill that leads to success for their subordinates to emulate. This leader modeling of desirable adaptable behaviors at work may have a moderating effect on the relationship between the employee's own adaptability and their job task performance. However, there is no existing research to support this moderation effect.

\section{Purpose of the Current Study}

The literature shows a clear positive relationship between employee adaptability and job performance. There are also clear relationships between leader adaptability and important outcomes such as leader effectiveness. Some research has been conducted by examining mediators of the relationship between employee adaptability and job performance, but there is a significant gap in research on moderators of this relationship. Studying the moderation of the employee adaptability to job performance relationship may produce empirical evidence supporting beneficial implications with both academic and practical purposes. The purpose of this research is to address that gap in the literature 
by investigating the moderating effect of leadership adaptability on the relationship between employee adaptability and job task performance.

Leadership adaptability will be the moderator in this work because previous research has shown significant positive outcomes for organizations and individuals. This study aims to show that leaders who are high in adaptability will model desirable adaptable behaviors, thereby demonstrating to employees that adaptable behaviors are beneficial to job performance. This will in turn increase the employees' job performance. Therefore, the following hypothesis was proposed;

Hypothesis: Leadership adaptability will have a moderating effect on the relationship between employee adaptability and job performance. More specifically, the relationship between employee adaptability and job performance will be stronger for employees who report their manager as highly adaptable than employees who report their manager as less adaptable. 


\section{Method}

\section{Participants}

Participants were part of my personal and professional network and were recruited via social media (e.g., Facebook and LinkedIn). A total of 163 individuals initially participated in the study. However, 38 participants were excluded from the analyses because they were either under the age of 18 or were unemployed. The final sample consisted of 125 individuals.

The demographic characteristics of these participants are reported in Table 1. The sample consisted of 33 males (26.4\%), 90 females (72.0\%), and two individuals who identified as non-binary (1.6\%). In terms of age, $61.6 \%$ of individuals were below the age of 35 , with $32.0 \%$ between the ages of 18 and 24 and $29.6 \%$ between the ages of 25 and 34. In terms of length of employment in their current positions, $68.0 \%$ of participants had been in their current position for less than four years $(39.2 \%$ for between one and three years and $28.8 \%$ for less than one year). Overall, the sample was predominantly female, young adults, and consisted of participants who were relatively new to their careers. 
Table 1

Demographic Characteristics of Participants $(N=125)$

\begin{tabular}{|c|c|c|}
\hline Variable & $n$ & $\%$ \\
\hline \multicolumn{3}{|l|}{ Gender } \\
\hline Male & 33 & 26.4 \\
\hline Female & 90 & 72.0 \\
\hline Non-binary/Other & 2 & 1.6 \\
\hline \multicolumn{3}{|l|}{ Age } \\
\hline 18-24 years & 40 & 32.0 \\
\hline $25-34$ years & 37 & 29.6 \\
\hline $35-44$ years & 16 & 12.8 \\
\hline $45-54$ years & 19 & 15.2 \\
\hline $55-64$ years & 13 & 10.4 \\
\hline \multicolumn{3}{|l|}{ Length of Employment } \\
\hline Less than 1 years & 36 & 28.8 \\
\hline $1-3$ years & 49 & 39.2 \\
\hline 4-6 years & 20 & 16.0 \\
\hline $7-10$ years & 7 & 5.6 \\
\hline More than 10 years & 13 & 10.4 \\
\hline
\end{tabular}

\section{Measures}

Job task performance-oriented adaptability of the employee. The job task

performance-oriented adaptability of the employee was measured with a scale composed of 18 items divided into six dimensions (solving problems creatively, dealing with uncertain and unpredictable work situations, learning work tasks, technologies, and procedures, demonstrating interpersonal adaptability, demonstrating cultural adaptability, and handling work stress). The items were adapted from Ployhart and Bliese's (2006) IADAPT-M scale, which contained 55 items assessing employees' adaptability on the six 
above mentioned dimensions plus the dimensions of handling work emergencies or crises and demonstrating physically oriented adaptability. Pertinent items from the I-ADAPT-M were retained. Items were included in the final measure if they measured one of the six relevant dimensions of adaptability and were written with proper psychometric formatting to increase the clarity, validity, and reliability of the measure. This means any items that measured an individual's ability to handle work emergencies or be physically adaptable or were written unclearly were not included in the final measure.

The scale utilized a 5-point Likert scale from 1 (Strongly Agree) to 5 (Strongly Disagree). Sample items for individual adaptability include, "I enjoy learning about cultures other than my own," which measured cultural adaptability; "I am an innovative person," which measured solving problems creatively; "I enjoy learning new approaches for conducting work," which measured learning work tasks, technologies, and procedures; "I am an open-minded person in dealing with others," which measured interpersonal adaptability; "I am stressed when I have a large work load," which measured handling work stress; and "I become frustrated when things are unpredictable," which measured dealing with uncertain and unpredictable work situations.

The responses to the individual adaptability items were averaged to create an overall adaptability score for each participant. The range of scores for overall adaptability was from 1.00 to 5.00 . Lower overall adaptability scores indicate that the participants were more adaptable overall, such that were easily able to adjust their behavior when faced with new and changing circumstances at work. High overall adaptability scores indicate that the participants were less adaptable overall; this means they struggled to adjust their 
behavior when faced with new and changing circumstances at work. The scale demonstrated high internal consistency $(\alpha=.80)$.

Job task performance-oriented adaptability of the manager. The job task performance-oriented adaptability of the manager was measured with a scale composed of 18 items divided into six dimensions (solving problems creatively, dealing with uncertain and unpredictable work situations, learning work tasks, technologies, and procedures, demonstrating interpersonal adaptability, demonstrating cultural adaptability, and handling work stress). The items were adapted from Ployhart and Bliese's (2006) IADAPT-M scale, which contained 55 items assessing employees' adaptability on the six above mentioned dimensions plus the dimensions handling work emergencies or crises and demonstrating physically oriented adaptability. Items measuring handling work emergencies or crises and demonstrating physically oriented adaptability were not included. Pertinent items from the I-ADAPT-M were retained. Items were included in the final measure if they measured one of the six relevant dimensions of adaptability and were written with proper psychometric formatting to increase the clarity, validity, and reliability of the measure. The items were adapted for the individuals responding to comment on their perception of their manager's adaptability.

The scale utilized a 5-point Likert scale from 1 (Strongly Agree) to 5 (Strongly Disagree). Sample items for perceived manager adaptability include, "My manager enjoys learning about cultures other than their own," which measured cultural adaptability; "My manager is an innovative person," which measured solving problems creatively; "My manager enjoys learning new approaches for conducting work," which 
measured learning work tasks, technologies, and procedures; "My manager is an openminded person in dealing with others," which measured interpersonal adaptability; "My manager gets stressed when they have a large work load," which measured handling work stress; and "My manager becomes frustrated when things are unpredictable," which measured dealing with uncertain and unpredictable work situations.

The responses to the perceived manager adaptability items were averaged to create an overall adaptability score for the participants' managers. The range of scores for overall adaptability was from 1.00 to 5.00. Lower overall adaptability scores indicate that the participants' managers were more adaptable; this means they easily adjusted their behavior when faced with new and changing circumstances at work. High overall all adaptability scores indicate that the participants' managers were overall less adaptable; this means they struggled to adjust their behavior when faced with new and changing circumstances at work. The scale demonstrated high internal consistency $(\alpha=.92)$.

Employee job performance. Employee job performance was measured with a 5-item scale. Some of the items were adapted from Onwezen, van Veldhoven, and Biron's (2014) Job Performance Measure, which contains nine items measuring job performance of employees. Four pertinent items from the Job Performance Measure were retained and adapted specifically for the purposes of the current study. Items were retained for the study if they were written with proper psychometric standards; this means any items that were double-barreled or unclear were not included in the final measure. The original scale from Onwezen et al. (2014) was written with the intention of being taken during the workday. One example of the originally worded items was "Today, I 
was suitable for a higher level role in my company." This wording, specifically the use of the word "today," implies the participants would be taking the survey during their typical workday or just after. The items were adapted for this study to accommodate the varying days and times when participants might answer the survey. For example, the same item was rewritten slightly to "I am suitable for a higher level role in my company." By excluding the word "today" and changing the tense of the item from past tense to present tense, participants were not limited to responding during or after their workday. The scale utilized a 5-point Likert scale from 1 (Strongly Agree) to 5 (Strongly Disagree). These items were reverse scored before calculating the overall job performance score. Sample items from this section include, "I demonstrate expertise in my job-related tasks," and "I could manage more responsibility than I currently have.

The remaining item was developed specifically for the purpose of the current research study. This item asked participants "In the last year, how did you perform compared to what was expected of you?" This item utilized a 5-point Likert scale of 1 (I performed greatly under what was expected of me), 2 (I performed slightly under what was expected of me), 3 (I performed as expected), 4 (I performed slightly above what was expected of me), and 5 (I performed greatly above what was expected of me).

The responses to all five performance items were averaged to create an overall job performance score. The possible range of scores for job performance was from 1.00 to 5.00. Lower scores indicated lower overall job performance; this means the participants performed less well than what was expected of them. Higher scores indicated higher 
overall job performance; this means participants performed above and beyond what was expected of them. The scale demonstrated low internal consistency $(\alpha=.53)$.

Participant demographics. Participant demographics were measured with four items (gender, age, status of employment, and length of employment). The first item measured participant age groupings (Under 18 years of age, 18-24 years of age, 25-34 years of age, 35-44 years of age, $45-54$ years of age, 55-64 years of age, over 65 years of age). The second item measured participant gender identification (female, male, other/non-binary). The third item measured participant employment status (yes, I am currently employed or no, I am not currently employed). The fourth item measured length of employment (less than 1 year, 1-3 years, 4-6 years, 7-10 years, more than 10 years).

\section{Procedure}

Data were collected through the online survey platform Qualtrics. Participation was solicited through personal networks. An anonymous link to the survey was posted on networking sites such as Facebook, LinkedIn, and Reddit. Members of the networking sites were informed that data was being collected for the present study. Participants were invited to click the link if they wished to participate and were encouraged to share it with others who they felt might be interested and willing to participate. This is known as “snowball” sampling.

Participants who clicked the link were taken to the consent form of the survey which stated their rights as participants. The consent form stated that participation was voluntary and confidential, and participants could exit the survey at any time. Participants were then instructed to click either "I consent, begin the study" or "I do not consent, exit 
the study." By clicking the "I consent" option, participants were brought to the first set of questions in the survey, which captured the demographics of the participants. At this point, participants were screened for the inclusion criteria of the study. To participate in the study, participants had to be at least 18 years of age and currently employed. Any participants who selected "Under 18 years of age" in the age group question, or "No" in the employment status question were taken to the end of the survey and thanked for their participation. Participants who indicated they were over 18 years of age and currently employed were shown the rest of the items in the survey. Participants were instructed to indicate their agreement with each statement by clicking on the appropriate option from the range of options. Upon completion of the survey, participants were shown a closing screen which thanked them for their participation. Once data collection was completed, the data were exported into the Statistical Package for the Social Sciences (SPSS) program (Version 25) for statistical analysis. 


\section{Results}

\section{Descriptive Statistics}

The means and standard deviations for the measured variables are shown in Table 2. Participants reported their own adaptability as moderately high $(M=2.17, S D=.44)$. This indicates that participants felt they were generally able to adjust their behavior as needed when interacting with others, solving problems, learning new skills, facing uncertainty, and dealing with stress at work. Analysis of the moderator, perceived manager adaptability, revealed participants reported moderately high levels of their perception of their managers' adaptability $(M=2.34, S D=.71)$. This suggests participants felt their managers were able to adjust their behavior as needed when interacting with others, solving problems, learning new skills, facing uncertainty, and dealing with stress at work. Finally, participants reported moderately high levels of job performance $(M=4.11, S D=.54)$. This indicates that overall, participants felt they exceeded expectations in their work task performance.

Table 2

Means, Standard Deviations, and Bivariate Correlations Among Variables $(N=125)$

\begin{tabular}{|c|c|c|c|c|c|c|}
\hline & Variable & M & $\mathrm{SD}$ & 1 & 2 & 3 \\
\hline & Employee Adaptability & 2.17 & .44 & -- & & \\
\hline 2. & Perceived Manager Adaptability & 2.34 & .71 & $.24 * *$ & -- & \\
\hline & Overall Job Performance & 4.11 & .54 & $-.30 * *$ & $.19 *$ & -- \\
\hline
\end{tabular}




\section{Pearson Correlations}

Pearson correlations were computed to evaluate how the variables were related. The Pearson correlations for the measured variables are shown in Table 2. There was a significant, moderately strong positive relationship between overall employee job task performance-oriented adaptability and the employee's overall perception of their manager's job task performance-oriented adaptability, suggesting that more adaptable employees viewed their managers as more adaptable, $r(123)=.24, p<.01$. There was a significant, moderately strong negative relationship between overall employee job task performance-oriented adaptability and the employee's overall perception of their own job performance, suggesting that more adaptable employees evaluated themselves as higher performers, $r(125)=-.30, p<.01$. There was a significant, moderately strong positive relationship between the employee's overall perception of their manager's job task performance-oriented adaptability and the employee's overall perception of their own job performance, suggesting that employees who rated their managers as less adaptable rated their own job performance as higher, $r(125)=.19, p=<.05$.

\section{Test of Hypothesis}

Two hierarchical multiple regression (MRC) analyses with two steps were conducted to test the hypothesis that leadership adaptability had a moderating effect on the relationship between employee adaptability and job performance. More specifically, the relationship between employee adaptability and job performance was postulated to be stronger for employees who report their manager is highly adaptable than employees who report their manager is less adaptable. 
In the first step, employee adaptability and perceived manager adaptability were entered as predictors to assess their relationship to overall performance. In the second step, the interaction between employee adaptability and perceived manager adaptability was added to explore its moderating effect. The hypothesis stated that perceived manager adaptability would moderate the relationship between employee adaptability and job performance.

As shown in Table 3 , employee adaptability and perceived manager adaptability were entered in the first step as independent variables. The first step revealed that these two variables explained $16 \%$ of the variance in overall performance, $R^{2}=.16, R^{2} a d j=.15$, $F(2,122)=11.52, p<.001$. Thus, the adaptability of the employees and their perceptions of their manager's adaptability significantly contributed to their overall job performance. Employee adaptability, $\beta=-.36, t=-4.24, p<.001$, had a significant, moderately strong negative unique contribution to the variance explained in job performance, indicating that more adaptable employees rated their overall performance as higher than less adaptable employees. Perceived manager adaptability, $\beta=.27, t=3.20, p<.01$, also had a significant, moderately strong positive unique contribution to the variance explained in job performance, such that employees who perceived their managers to be less adaptable rated their overall performance better than when their managers perceived to be more adaptable.

In the second step, the interaction between employee adaptability and perceived manager adaptability was entered. This variable represented the moderating effect of perceived manager adaptability on relationship between employee adaptability and job 
performance. The moderating variable did not account for a significant amount of variance above and beyond the direct effects of employee adaptability and perceived manager adaptability, $\Delta R^{2}=.002, F(1,121)=.29, p>.05$. Therefore, the relationship between employee adaptability and job performance was not moderated by perceived manager adaptability, indicating that an employees' perceptions of their managers' adaptability did not significantly affect the relationship between the employees' own adaptability capabilities and their overall job performance. Thus, the research hypothesis was not supported.

Table 3

Hierarchical MRC for the Moderating Effect of Perceived Manager Adaptability (Overall Job Performance)

\begin{tabular}{llccc}
\multicolumn{1}{c}{ Predictor } & \multicolumn{1}{c}{$\Delta \mathrm{R}^{2}$} & $\beta$ \\
\hline Step 1: & $\begin{array}{l}\text { Adaptability } \\
\text { Individual Adaptability } \\
\text { Perceived manager adaptability }\end{array}$ & $.16^{* * *}$ & $.16^{* * *}$ & \\
& & & $-.36^{* * *}$ \\
Step 2: & $\begin{array}{l}\text { Individual x Perceived Manager } \\
\text { Adaptability }\end{array}$ & $.16^{* * *}$ & .00 & \\
& $\begin{array}{l}\text { Individual Adaptability x Perceived Manager } \\
\text { Adaptability }\end{array}$ & & & -.27 \\
& & & \\
\hline & $* \mathrm{p}<.05$ & $* * \mathrm{p}<.01$ & $* * * \mathrm{p}<.001$
\end{tabular}

A second hierarchical MRC analysis was conducted to determine if the overall performance score, which was calculated from all five performance items, would differ from the results of just the first performance item which asked "In the last year, how did you perform compared to what was expected of you?" This additional analysis was conducted because this item measured performance differently than the other 
performance items. The four remaining performance items asked participants to rate their level of agreement to statements regarding specific aspects of their work, such as the amount of responsibility they could manage and their ability to fulfill the requirements of their jobs. The first performance item differed as it asked participants to evaluate their performance overall in the past year. This item was therefore a global self-evaluation of job performance compared to the other performance items.

As shown in Table 4, employee adaptability and perceived manager adaptability were entered in the first step as independent variables. The first step revealed that these two variables explained $5 \%$ of the variance in the global self-evaluation of job performance, $R^{2}=.05, R^{2} a d j=.03, F(2,122)=2.97, p>.05$. Thus, the adaptability of the employees and the perceived adaptability of their manager did not significantly contribute to the global self-evaluation of job performance. Only perceived manager adaptability had a significant unique contribution to variance explained in global self-evaluation of job performance, $\beta=.21, t=2.32, p<.05$, indicating a moderately strong positive relationship with global self-evaluation of job performance. This means employees who perceived their managers to be less adaptable rated their performance in the last year more highly than those who perceived their managers to be more adaptable. Unlike the first analysis, which included the four performance items measuring specific aspects of work, employee adaptability was not uniquely related to the global self-evaluation of job performance, $\beta=-.12, \mathrm{t}=-1.27, \mathrm{p}>.05$.

In the second step, the interaction between employee adaptability and perceived manager adaptability was entered. This variable represented the moderating effect of 
perceived manager adaptability on relationship between employee adaptability and job performance. The moderating variable did not account for a significant amount of variance above and beyond the direct effects of employee adaptability and perceived manager adaptability, $\Delta R^{2}=.02, F(1,121)=2.26, p>.05$. Therefore, the relationship between employee adaptability and global self-evaluation of job performance was not moderated by perceived manager adaptability, indicating that perceived adaptability of managers did not significantly affect the employees' own adaptability capabilities and their own evaluation of their job performance.

Table 4

Hierarchical MRC for the Moderating Effect of Perceived Manager Adaptability (Global Self-Evaluation of Job Performance)

\begin{tabular}{llccc}
\multicolumn{1}{c}{ Predictor } & $\mathrm{R}^{2}$ & $\Delta \mathrm{R}^{2}$ & $\beta$ \\
\hline Step 1: & $\begin{array}{l}\text { Adaptability } \\
\text { Individual Adaptability } \\
\text { Perceived manager adaptability }\end{array}$ & .05 & .05 & \\
Step 2: & & & -.12 \\
& $\begin{array}{l}\text { Individual x Perceived Manager } \\
\text { Adaptability } \\
\text { Individual Adaptability x Perceived } \\
\text { Manager Adaptability }\end{array}$ & .07 & .02 & \\
& & & & $-.81^{*}$ \\
\hline & $* \mathrm{p}<.05$ & $* * \mathrm{p}<.01 \quad * * * \mathrm{p}<.001$
\end{tabular}




\section{Discussion}

The purpose of study was to evaluate the moderating effect of perceived manager adaptability on the relationship between employees' adaptability and their job performance. The research hypothesis stated that perceived manager adaptability would have a significant moderating effect on the relationship between employee adaptability and employee job performance such that the relationship between employee adaptability and job performance would be stronger for employees who reported their manager as highly adaptable than employees who reported their manager as less adaptable.

\section{Summary of Findings}

In the first hierarchical regression analysis, both employee adaptability and perceived manager adaptability were found to have significant contributions to the variance in overall job performance. Employee adaptability had a significant negative contribution, meaning that more adaptable employees reported better job performance overall than less adaptable employees. However, perceived manager adaptability had a significant positive relationship with job performance indicating that employees who reported their manager as more adaptable tended to report lower job performance than employees who reported their manager as less adaptable. The results did not indicate a significant moderating effect of perceived manager adaptability on the relationship between employee adaptability and job performance; therefore the hypothesis was not supported.

In the second hierarchical regression analysis, only perceived manager adaptability had a significant contribution to the variance in global self-evaluation of job performance. Perceived manager adaptability had a significant positive contribution, 
indicating that employees who reported their manager as more adaptable reported lower global self-evaluations of job performance than employees who reported their manager as less adaptable. Like the first analysis, the results did not indicate a significant moderating effect of perceived manager adaptability on the relationship between employee adaptability and job performance.

\section{Theoretical Implications}

Previous research indicated that adaptable employees are better performers (Kim et al., 2017; Sony \& Mekoth, 2016; Parent \& Levitt, 2009). However, the results of this study only partially supported those findings. The unique relationship between employee adaptability and job performance was only significant when job performance was measured with an overall score than with a single global self-evaluation score. This could indicate that employee adaptability is related to multiple facets that make up one's perception of their job performance, such as one's capability to manage responsibility and fulfill the requirements of their role. Adaptable employees may evaluate their adaptability as beneficial to certain aspects of their performance, but not to their overall performance. They may have felt there were external factors they could not change that affected their overall job performance. Job performance may be viewed as multidimensional and therefore adaptability may be viewed as impactful only on one's ability to handle responsibility, fulfill the requirements of the job, and fit into their position in the organization. Therefore, the results of this study lend partial support to the existing idea that employee adaptability is a predictor of critical organizational and individual outcomes. 
The gap identified in the existing body of literature was a lack of research around moderation. Previous research focused extensively on mediation of the relationship between employee adaptability and job performance (Cullen et al., 2013; Wang et al., 2011). While this study helped fill some of the gap where moderation had not been examined, this study's findings that leadership adaptability did not moderate the relationship between employee adaptability and job performance may give some insight into why there are not any studies describing moderation effects. It may be that past research similarly uncovered a lack of moderation of the relationship between employee adaptability and job performance and thus was considered not worthy of publishing or continuation of the work.

However, other variables may have moderating effects on the relationship between employee adaptability and job performance. It could be that individual-level variables such as employee gender, age, or tenure with the organization affect the relationship between employee adaptability and job performance. For example, employees with longer tenure at their organizations may be more adaptable due to their increased experience and may perform better as a result. There may also be organizational-level variables that could moderate the relationship, such as the size of the organization, the industry the organization is in, or the culture of the organization. For example, employees in small organizations may be encouraged to adapt more than employees in large organizations because the organization requires employees to "wear multiple hats" in order to function with a relatively lean staff. 
Leader adaptability was noted to be an important characteristic in research conducted by Bartone et al. (2013) and Hyllengren (2017). Previous research found relationships between leader adaptability and leader effectiveness (Bartone et al, 2013) as well as positive outcomes in unexpected situations (Hyllengren, 2017). These direct effects are likely to support a positive relationship between leader adaptability and their subordinates' performance.

Interestingly, this research study found an opposite relationship. Perceived manager adaptability in this study had a negative relationship with employee job performance, such that employees who reported their managers as being less adaptable reported their own performance as being higher than employees who reported their managers as more adaptable. This could suggest that less adaptable managers reward and praise adaptable behaviors in their employees despite not modeling those behaviors themselves. These less adaptable managers may feel that adaptability is a unique trait that is highly valuable but not common or easily taught to employees. Therefore, managers may give additional encouragement and support to employees who naturally demonstrate these desirable behaviors.

The inverse relationship between perceived manager adaptability and job performance could also indicate that highly adaptable managers are less likely to reward or call out adaptable behaviors as a positive characteristic in their subordinates. These highly adaptable managers may not view adaptability as a unique advantage but as a foundational requirement of the job. This may mean highly adaptable employees get less recognition for their innovative ideas and problem solving skills and thus may feel they 
are not performing above and beyond their expected level due to their adaptability. Additionally, highly adaptable managers may feel adaptability is a teachable skill and may single out employees to attempt to develop their adaptability capabilities. This may mean that employees who are singled out for development may feel their performance is not up to the expectations of their managers and thus rate themselves as having lower job performance.

The findings of this study are in line with the findings of Tsui et al. (2002) that similarities between supervisors and subordinates tend to increase extra-role behaviors but not in-role job performance. In the findings of the present study, when the dyads were dissimilar such as highly adaptable employees with less adaptable managers, employees tended to report higher levels of job performance. This could indicate that when faced with a less adaptable manager, employees view their adaptable behavior as an advantage and thus may rate their performance higher. They may view the dissimilarity between themselves and their supervisors as more meaningful and impactful than employees in dyads of similarity. This suggests that managers who are dissimilar in their adaptability level from their employees may have more of a pronounced effect on employees than managers who are similar in their adaptability level.

\section{Practical Implications}

The direct effects of employee adaptability on job performance may have practical implications. In organizations, the adaptability capabilities of employees may be a key metric to understand. By measuring adaptability, organizations and human resources professionals can better predict which employees will adapt easily to learning new 
technology and which may require additional trainings and time to adjust. Understanding adaptability may help leaders select individuals who will perform well on projects and teams that require individuals to adjust regularly to changing timelines, expectations, or conditions. Leaders may be able to make strategic business decisions more confidently by predicting how much resistance their workforce may have to changes in business direction or processes.

Practical implications of this research may be found in the relationships between perceived manager adaptability, employee adaptability, and employee job performance. Based on adaptability scores, human resources professionals can evaluate the employee/manager dyads for compatibility. The results of this study suggested that a highly adaptable employee will perform better when paired with a less adaptable manager than with a more adaptable manager. For highly adaptable employees, pairing them with less adaptable managers may increase the effectiveness of their adaptability. The adaptable employee's ability to work with diverse others and solve problems in creative ways to achieve goals may be a relief to managers who struggle to come up with innovative solutions on their own. Managers may feel assured that their highly adaptable employees can work independently and will not rely on their managers to solve problems for them. This may allow managers to focus on their less adaptable employees who may require more manager oversight to resolve issues.

The practical implications of understanding perceived manager adaptability and employee adaptability can be beneficial to less adaptable employees. Less adaptable employees may have negative feelings when paired with highly adaptable managers. The 
results of this study found that less adaptable employees reported better job performance when they reported having a less adaptable manager. This may indicate they feel less challenged by a manager who is similar to them and does not push them beyond their capabilities by encouraging constant innovation and flexibility. Human resources professionals can use this knowledge to create compatible pairings of managers and employees by ensuring that less adaptable employees feel supported by their manager. Additionally, human resources professionals may support less adaptable employees by developing targeting trainings that build problem solving skills and resilience to uncertainty.

This study found that highly adaptable employees do perform well with highly adaptable managers, however they may not feel like they are performing above expectations because their manager may consider innovation and flexibility to be fundamentally important to performing the role to expectation. Human resources professionals can apply the findings of this study to help retain highly adaptable employees by placing them with managers who value their innovation as a beneficial additional skill they themselves do not possess or are well skilled in, thus increasing the employees' sense of self-worth. For situations where a highly adaptable employee must be paired with a highly adaptable manager, managers could be coached to look for and recognize employees when they solve a problem creatively or bring cooperation and harmony to diverse teams. Calling out adaptive behaviors as beneficial and meaningful to the overall success of teams and organizations may increase adaptable employees' morale and job satisfaction, which in turn could promote retention. Recognition from managers 
may signal to employees that their contributions are meaningful and important. These employees may then be more likely to feel a connection to the organization and less likely to seek opportunities elsewhere.

Practical implications can be gleaned from the nature of the variables. Since the data collected relied on employee perceptions, human resources professionals can gather valuable insights into the thoughts and feelings of their employees. The highly adaptable employee may actually perform above what is expected of them but may feel they do not stand out from their peers when their coworkers and manager all exhibit similar adaptive behaviors. Additionally, perceived manager adaptability may be different from the level of adaptability perceived by the employee. Managers and human resources professionals should pay attention to employee sentiments regarding their managers and their job performance. If high performing employees describe feeling like their performance is lacking, managers and human resources professionals should take action to better understand what is causing those feelings. It could be that regularly adapting to uncertainty and new situations does not give employees a sense of satisfaction or consistency, which could lead to burnout. To mitigate this, managers and human resources professionals could develop resources that support employees who adapt frequently.

\section{Strengths}

One strength of this study was that it focused on moderation of the relationship between employee adaptability and job performance. Moderation of that relationship had not previously been examined; thus, this research helped to fill the gap. Another strength 
of this study was the highly diverse participant sample. Although participants' field of work and country were not directly measured, recruiting participants from personal networks allowed the sample to potentially span many industries, jobs, and locations. This makes the findings more generalizable than previous research conducted explicitly in more narrow settings, such as studies conducted solely with military personnel (Bartone et al., 2013; Hyllengren, 2017), casino workers (Kim et al., 2017), or in specific countries (Sony \& Mekoth, 2016; Wang et al., 2011).

A third strength of this study was the method of assessing job performance. Previous research assessed job performance through supervisor ratings (Wang et al., 2011; Cullen et al., 2013; Parent \& Levitt, 2009), or through industry specific measures (Kim et al., 2017). This study utilized generalizable performance items, thus allowing performance data to be gathered from participants simultaneously with adaptability data. The generalizability of the performance items is a strength that allowed for participants from many different industries to respond and allowed their performance to be compared. Previous research was isolated to one industry and could not easily be compared to other kinds of work.

\section{Limitations and Suggestions for Future Research}

This study is not without its limitations. One limitation of the study was that it was completely self-report. Participants in this study rated their managers' adaptability rather than having the managers rate themselves. By relying on participants' perceptions, perceived manager adaptability scores may have differed from actual manager adaptability. Indeed, the Cronbach's alpha for perceived manager adaptability was higher 
than the Cronbach's alpha for employee adaptability. This could indicate that employees tended to think about their own adaptability in a more complex way than how they thought about their manager's adaptability as a result of a halo effect. The possible halo effect implies that participants may have rated their managers' adaptability in a less detailed way than how they rated their own adaptability. This could be a factor in the unexpected relationship between perceived manager adaptability and performance. Future research should solicit managers' own self-reports of their adaptability to reduce potential halo effects.

Job performance was assessed by asking participants to rate themselves rather than collecting objective performance data from the participant's managers or Human Resources departments. Relying on employees to self-report their performance may have resulted in employees inflating their job performance as higher than how they perform in reality. Future research should try to mitigate this by gathering performance data from employees' managers or from their Human Resources departments to obtain more objective performance data.

Another limitation of this study was in the participant sample. While the participant population was diverse in terms of industry and location, the sample was overwhelmingly female. Males and non-binary individuals were minorities in the sample. This may have had an effect on the results. Females may have different perceptions of perceived manager adaptability than males or non-binary individuals. Previous research also has demonstrated that females rated their own performance lower than males (Swanson \& Lease, 1990; Hackett \& Campbell, 1987). By having such large gender differences in the 
sample, the results may not be generalizable to wider populations. Future research should seek to have evenly distributed gender proportions in the sample to reduce any potential gender biases.

Another limitation is the wording of the survey items. Of the 36 adaptability items in the survey, the reverse-scored items had the highest variability in responses. These items were written as presumably less desirable behaviors and traits. One example of the reverse-scored items was "I overreact to stressful news." Normally scored items tended to have less variability in responses and were written with more desirable behaviors and traits; one example of this kind of item is "I am an innovative person." This could indicate that the reverse-scored items prompted participants to think more deeply about their adaptability and the adaptability of their manager than the more overtly positive items. Future research should consider developing more reverse-scored survey items to increase response variability.

This study found an interesting relationship between perceived manager adaptability and job performance such that employees who reported their managers as being more adaptable reported lower job performance than employees who reported their managers as being less adaptable. Future research could examine the possible reasons behind this relationship by surveying managers on their beliefs regarding the importance of adaptability in their employees. Additionally, because the present study relied on employee perception, future research ought to compare perceived versus actual adaptability of their manager and employee job performance. It is possible that employee 
perception affected the nature and direction of the relationships between employee adaptability, perceived manager adaptability, and job performance.

Finally, the data were collected during the global COVID-19 pandemic. Governments and health authorities ordered widespread shutdowns and restrictions in order to reduce health risks and the spread of the virus. In response to this crisis, organizations with the capability for remote work transitioned most if not all of their workforce to work fulltime from home. Organizations where remote work was not a feasible solution were faced with rapid implementation of workplace guidelines such as social distancing, increased sanitation, reduced numbers of workers, required face coverings, and temperature checks to reduce possibility of transmission and keep their employees safe. Businesses unable to adjust to the new workplace guidelines were forced to lay off employees or close indefinitely.

In such unprecedented circumstances, employees and managers were forced to adapt in many ways, either to new work from home situations, to new workplace guidelines, or to sudden job loss. Therefore, surveying employees about adaptability and job performance during this time may have produced unique results. This could explain the unusual relationship between reported perceived manager adaptability and job performance. It could be that employees felt their managers did not respond well to COVID-19 related changes and thus rated their managers' ability to adapt in general as poor. These employees may have felt they were able to adapt far better than their managers and thus were better suited to perform well when faced with challenges to their normal working conditions. Future research should replicate this study in a time when 
working conditions are not affected by external factors such as a global pandemic. This could reveal that the circumstances during which the data for this study was gathered influenced the results.

\section{Conclusion}

Adaptability is an important characteristic in the workplace. Adaptable employees handle new situations and problems better than unadaptable employees. As a result, highly adaptable employees perform better and more consistently. Perceived manager adaptability is also an important characteristic in the workplace and understanding how employees and managers adapt differently is critical to ensuring effective workplace dynamics. Managers and organizations can use this knowledge to their benefit and create teams and supervisor-subordinate relationships that enable highly adaptable employees to thrive and use their adaptability for achieving the goals of their organizations. 


\section{References}

Bartone, P. T., Kelly, D. R., \& Matthews, M. D. (2013). Psychological hardiness predicts adaptability in military leaders: A prospective study. International Journal of Selection and Assessment, 21, 200-210.

Campbell, J. P., McCloy, R. A., Oppler, S. H., \& Sager, C. E. (1993). A theory of performance. In N. Schmitt \& W. C. Borman (Eds.), Personnel selection in organizations. (pp. 35-70). Jossey-Bass Publishers.

Cullen, K. L., Edwards, B. D., Casper, W. C., \& Gue, K. R. (2014). Employees' adaptability and perceptions of change-related uncertainty: Implications for perceived organizational support, job satisfaction, and performance. Journal of Business and Psychology, 29, 269-280.

Dries, N., \& Pepermans, R. (2012). How to identify leadership potential: Development and testing of a consensus model. Human Resource Management, 51, 361-385.

Eisenberger, R., Huntington, R., Hutchison, S., \& Sowa, D. (1986). Perceived organizational support. Journal of Applied Psychology,71, 500-507.

Hackett, G., \& Campbell, N. K. (1987). Task self-efficacy and task interest as a function of performance on a gender-neutral task. Journal of Vocational Behavior, 30, 203215.

Hyllengren, P. (2017). Military leaders' adaptability in unexpected situations. Military Psychology, 29, 245-259.

Jiang, Z. (2017). Proactive personality and career adaptability: The role of thriving at work. Journal of Vocational Behavior, 98, 85-97.

Kim, P. B., Kim, S., Kim, S. S., \& Kim, J. (2017). Organizational drivers and outcomes of casino employees' work adaptability. Journal of Hospitality Marketing \& Management, 26, 276-296.

Kristof-Brown, A. L., Zimmerman, R. D., Johnson, E. C. (2005). Consequences of individuals' fit at work: A meta-analysis of person-job, person-organization, persongroup, and person-supervisor fit. Personnel Psychology, 58, 281-342.

Martin, A. J., Nejad, H., Colmar, S., \& Liem, G. A. D. (2012). Adaptability: Conceptual and empirical perspectives on responses to change, novelty and uncertainty. Journal of Psychologists and Counsellors in Schools, 22, 58-81. 
Onwezen, M. C., van Veldhoven, M. J. P. M., \& Biron, M. (2014). The role of psychological flexibility in the demands-exhaustion-performance relationship. European Journal of Work and Organizational Psychology, 23, 163-176.

Parent, J. D., \& Levitt, K. (2009). Manager vs. employee perceptions of adaptability and work performance. Business Renaissance Quarterly, 4, 23-48.

Ployhart, R. E., \& Bliese, P. D. (2006). Individual adaptability (I-ADAPT) theory: Conceptualizing the antecedents, consequences, and measurement of individual differences in adaptability. In C. S. Burke, L. G. Pierce \& E. Salas (Eds.), Understanding adaptability: A prerequisite for effective performance within complex environments. (pp. 3-39). Emerald Group Publishing Limited.

Pulakos, E. D., Arad, S., Donovan, M. A., \& Plamondon, K. E. (2000). Adaptability in the workplace: Development of a taxonomy of adaptive performance. Journal of Applied Psychology, 85, 612-624.

Rhoades, L., \& Eisenberger, R. (2002). Perceived organizational support: A review of the literature. Journal of Applied Psychology, 87, 698-714.

Savickas, M. L. (1997). Career adaptability: An integrative construct for life-span, lifespace theory. Career Development Quarterly, 45, 247-259.

Shore, L. M., \& Shore, T. H. (1995). Perceived organizational support and organizational justice. In R. Cropanzano \& K. M. Kacmar (Eds.), Organizational politics, justice, and support: Managing social climate at work. (pp. 149-164). Quorum Press.

Sony, M., \& Mekoth, N. (2016). The relationship between emotional intelligence, frontline employee adaptability, job satisfaction and job performance. Journal of Retailing and Consumer Services, 30, 20-32.

Swanson, J. L., \& Lease, S. H. (1990). Gender differences in self-ratings of abilities and skills. The Career Development Quarterly, 38, 347-359.

Tsui, A. S., Porter, L. W., \& Egan, T. D. (2002). When both similarities and dissimilarities matter: Extending the concept of relational demography. Human Relations, 55, 899-929.

Turner, J. C. (1985). Social categorization and the self-concept: A self-cognitive theory of group behavior. In E. J. Lawler (Ed.), Advances in group processes: Theory and research. (Vol. 2, pp. 77-122). JAI Press.

Turner, J.C. (1987). Rediscovering the social group: A self-categorization theory. Blackwell. 
Wang, M. O., Zhan, Y., McCune, E., \& Truxillo, D. (2011). Understanding newcomers' adaptability and work-related outcomes: Testing the mediating roles of perceived P-E fit variables. Personnel Psychology, 64, 163-189. 


\section{Appendix}

Survey Items

Job task performance-oriented adaptability of the individual

Creativity

1. I am an innovative person

2. I am able to look at problems from a multitude of angles

3. I am good at developing innovative solutions to complex problems

Cultural

1. I enjoy learning about cultures other than my own

2. I work well with diverse others

3. I feel comfortable interacting with others who have different values and customs

Interpersonal

1. I am an open-minded person in dealing with others

2. I try to be flexible in dealing with others

3. I adapt by behavior to get along with others

Learning

1. I enjoy learning new approaches for conducting work

2. I quickly learn new methods to solve problems

3. I am continually learning new skills for my job

Uncertainty

1. I am able to make effective decisions without all the relevant information

2. I become frustrated when things are unpredictable $(\mathrm{R})$

3. I perform well in uncertain situations

Work Stress

1. I overreact to stressful news (R)

2. I am easily rattled when my schedule is too full (R)

3. I am stressed when I have a large workload (R)

Job task performance-oriented adaptability of the manager

Creativity

1. My manager is an innovative person

2. My manager is able to look at problems from a multitude of angles

3. My manager is good at developing innovative solutions to complex problems 
Cultural

1. My manager enjoys learning about cultures other than their own

2. My manager works well with diverse others

3. My manager feels comfortable interacting with others who have different values and customs

Interpersonal

1. My manager is an open-minded person in dealing with others

2. My manager tries to be flexible in dealing with others

3. My manager adapts their behavior to get along with others

Learning

1. My manager enjoys learning new approaches for conducting work

2. My manager quickly learns new methods to solve problems

3. My manager is continually learning new skills for their job

Uncertainty

1. My manager is able to make effective decisions without all the relevant information

2. My manager becomes frustrated when things are unpredictable $(\mathrm{R})$

3. My manager performs well in uncertain situations

Work Stress

1. My manager overreacts to stressful news (R)

2. My manager gets easily rattled when their schedule is too full (R)

3. My manager gets stressed when they have a large workload (R)

Employee job performance

1. In the last year how did you perform compared to what was expected of you?

2. I demonstrate expertise in my job related tasks

3. I fulfill all the requirements of my job

4. I could manage more responsibility than I currently have

5. I am suitable for a higher level role in my company

(R) indicates reverse scored item 